\title{
Expounding the Construction Technical Measures of Fair-Faced Concrete Construction
}

\author{
Chenguang Liu \\ Shandong University of Arts, 250300
}

\begin{abstract}
Due to the acceleration of urbanization in China, construction technology in the construction field has also been continuously developed. The fair-faced concrete is often referred to as decorative concrete. It is a new type of concrete that has been continuously developed as people's demands for architectural decoration and it becomes more widely used in modern construction projects. In this paper, by introducing the types and composition of fair-faced concrete, a series of fair-faced concrete construction technical measures, as well as pouring and conservation measures, have been proposed in conjunction with actual construction projects, and examples have been analyzed in order to better apply the fair-faced concrete technology into modern buildings.
\end{abstract}

\section{Type of Fair-Faced Concrete}

Generally speaking, the fair-faced concrete is a kind of special concrete. It has the advantage of being able to maintain a certain sense of beauty without any modification after natural shaping, and also has a special texture of the concrete raw material, so it belongs to a kind of decorative concrete.

At present, there are three types of fair-faced concrete on the market: standard plain concrete, formlining fair-faced concrete, and decorative fair-faced concrete.

Standard fair-faced concrete is the most pristine of the three types of fair-faced concrete. It only imparts a simple texture through the natural state and color of the concrete after drying, and it also has a unique natural charm.

Compared with the simplicity of plain concrete, the surface-mounted fair-faced concrete is more demanding on the texture and color of the surface. In addition, the surface is smoother, and the lines have a certain degree of regularity.

Formlining concrete can meet the requirement of decorative building for the concrete after molding. Most of the concrete lines after molding have been specially designed to conform to the modified architectural style, and the requirements for concrete forming technology also are the highest.

\section{Role of Fair-Faced Concrete in Construction Engineering}

\subsection{Reduce Construction Costs}

Because the traditional concrete produces a lot of plaster in the process of use, resulting in the waste of materials, and the use of traditional concrete is more complicated, so the application of fair-faced concrete can effectively reduce construction costs, and by simplifying the use process, it can shorten the construction time and reduce Labor costs. In the past, to achieve the effect of decorating the wall surface, it was necessary to attach decorative tiles or stones to the concrete, which was affected by the fit. The possibility of damaging the wall surface for a long time was high, and the maintenance cost of the tiles or stones was high. However, for the fair-faced concrete, although its own cost is higher than that of the conventional concrete, the overall construction cost will be greatly reduced in view of the decrease in the decoration cost.

\subsection{Fair-Faced Concrete has a Special Decorative Aesthetic}

Compared with the modern architecture, which has undergone major renovations, the fair-faced concrete has a unique charm. Without the addition of various decorations in the later period, the appearance of the fair-faced concrete relying solely on the texture of its own material is enough to show a simple and natural beauty, and it formed its own elegant and simple style in the field of architectural decoration, giving a sense of intimacy. The fair-faced concrete is smooth and flat, and it feels warm. In general, buildings that are decorated with fair-faced concrete are aesthetically pleasing to other decorative materials, and the use of fair-faced concrete walls or columns is more solid and reliable, resistant to the challenges of various environments, and it will not be arbitrarily damaged. That is why the fair-faced concrete is often called green concrete. 


\section{Technical and Decorative Effect Requirements of Fair-Faced Concrete}

\subsection{Technical Requirements of Fair-Faced Concrete}

Up to now, China has not issued the relevant quality requirements for fair-faced concrete, and there is no corresponding department has accepted it yet. However, in actual use, the application of fair-faced concrete satisfies the "Construction and Acceptance Specifications for Concrete Structure Engineering". During the construction process, the color, flatness, and texture of finished concrete after shaping have corresponding specifications, and since it is a one-time pouring,so the safety requirements after molding will not drop.

Table 3-1 Allowable deviations and requirements of fair-faced concrete

\begin{tabular}{c|c|c|c|c|c}
\hline \hline Smoothness & The surface \\
Foughness & colour & crack & bubble \\
Fairness & $\begin{array}{c}\text { Comply with the } \\
\text { construction } \\
\text { quality } \\
\text { requirements of } \\
\text { the senior } \\
\text { plastering, the } \\
\text { construction } \\
\text { deviation does not } \\
\text { exceed 2mm }\end{array}$ & $\begin{array}{c}\text { Toughness, good flatness, } \\
\text { uniform color, no obvious } \\
\text { concavity }\end{array}$ & $\begin{array}{c}\text { Requires no } \\
\text { visible color } \\
\text { difference at } \\
8 \mathrm{~m}\end{array}$ & $\begin{array}{c}\text { The maximum } \\
\text { width of } \\
\text { surface cracks } \\
\text { does not } \\
\text { exceed } \\
0.15 \mathrm{~mm} ; \\
\text { normal type } \\
\text { plain concrete } \\
\text { does not } \\
\text { exceed } 0.2 \mathrm{~mm}\end{array}$ & $\begin{array}{c}\text { Strict protection measures } \\
\text { are taken so that the } \\
\text { concrete after molding is } \\
\text { as small as possible and } \\
\text { distributed as evenly as } \\
\text { possible. The maximum } \\
\text { diameter does not exceed } \\
3 \text { mm, and density does } \\
\text { not exceed }\end{array}$ \\
\hline \hline
\end{tabular}

\subsection{Fair-Faced Concrete Decoration Effect Requirements}

The decorative effect of fair-faced concrete should be realized through computer simulation application effects before construction, including the appearance effect, construction quality, etc., must be analyzed by relevant professionals. The visual appearance of the fair-faced concrete should be uniform in color, and the design of the sewing strip should not exceed $5 \mathrm{~mm}$ to avoid the loss of beauty. The seams should be smooth, natural or straight. The drilled holes and bolts on the fair-faced concrete should be treated accordingly so that it does not affect the flatness and appearance of the entire wall surface. The decorative wall surface with good decorative effect also has a certain correlation with the quality of the entire construction project.

\section{Fair-Faced Concrete Construction Technology Measures}

Since the processes are similar, this article only introduces the actual construction technology of standard plain fair-faced concrete in detail. The other two types of construction technologies are similar, but the requirements at the details are different.

\subsection{Pre-construction Precautions}

Before construction, construction personnel shall roughly determine the surface area of clear concrete in the actual project according to the design drawings, and inspect the design embedded parts such as bolts, drill holes, etc., and make corresponding special designs to meet the later design changes and construction. The process damages the entire finished product. The construction personnel's operating skills should be skilled, because skilled construction personnel can not only reduce the construction time, but also because they have a deeper understanding of the drawings, and the actual construction can be consistent to reduce the risk of change in the drawings .

\subsection{Construction Process of Fair-Faced Concrete}

\subsubsection{Template Engineering}

In the first step of formwork engineer's fair-faced concrete construction, when the formwork project guarantees the basic requirements of structural engineering load-bearing, it should try to maintain the overall aesthetic sense of the architectural style. Design templates should follow reasonable guidelines for rational design.

The classification of actual shear wall fair-faced concrete includes: full-steel large formwork, lightweight steel large formwork, wooden frame plywood and so on. The bamboo glue board and the multilayer board can be assembled to form a beam board template, and the support is often used full house scaffolding.

The selection principle of the template is to select a large template as far as possible to meet the quality and design requirements, so that the amount of construction will be reduced and the type of template required will be reduced accordingly. During the layout of the template, the length and width of the same template should be 
staggered to avoid the risk of uneven force structure. The supporting structure of the formwork should be ensured, and a sufficient number of fittings can be selected. When the template is assembled, all the nails should be nailed to the inside of the template at $1.5 \mathrm{~mm}$, and the appearance of the template will not be affected after the tool is used for leveling.

For the treatment of the column template, the method of fixing the scaffold tube by pulling the bolt should be adopted. Prior to the framing of the column template, it is first ensured that the inside of the column is clean, and the residual impurities are cleaned out with ink lines outside the template to show the axis and align it with the axial direction above. In order to prevent the deviation of the column template, a line drop is used for detection and adjustment every $10 \mathrm{~mm}$.

For the beam formwork, before using it, it is necessary to determine the required size of the template according to the design drawings. An adjustable support shall be placed on the pole, and after the support level is reached, wooden dimensions of a well-designed wooden square may be laid on it. The method of laying is to lay a good layer and continue to lay the other layer at intervals of $250 \mathrm{~mm}$. The squareness of the amount of wood should be good. After the beam bottom mold is applied to the paved wooden squares, the two-sided molds can be processed after being fixed, and the bolts and scaffolds are used for reinforcement after being processed.

Some small structural processes are as follows:
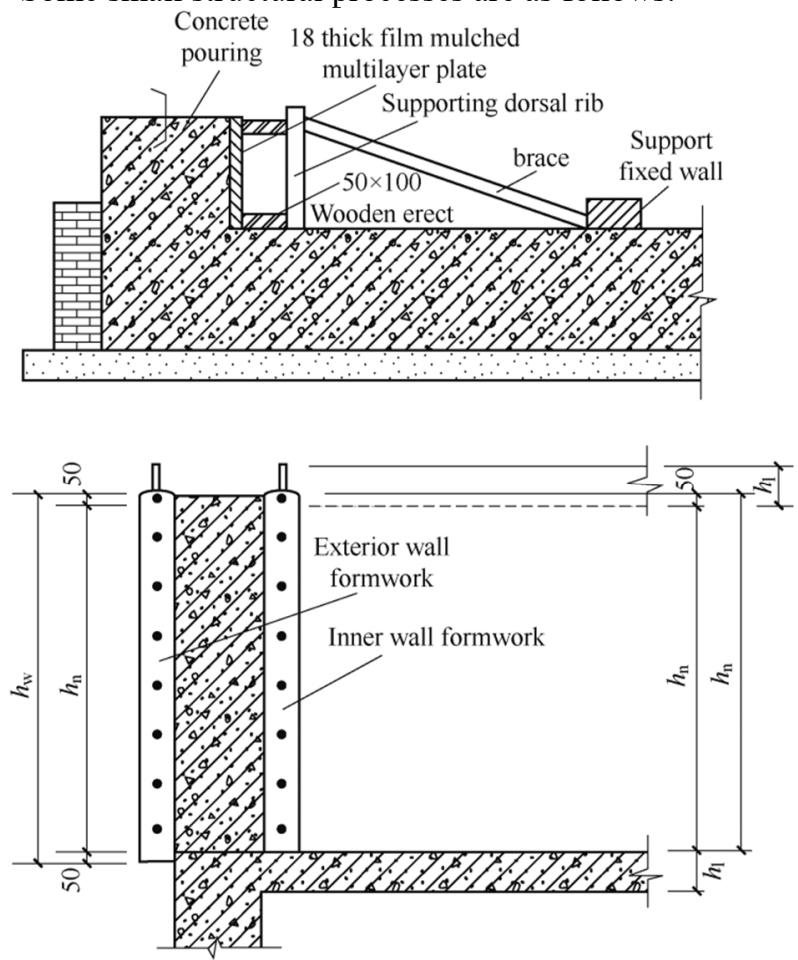

Figure 1 staircase node processing

(1) Node Processing

a. Inter-floor node processing

The node processing between floors is often performed in the form of an architectural model. As shown in Fig. 1, a hanging mould with a height of about $180 \mathrm{~mm}$ is constructed on the outer wall of the concrete slab to be poured. Firstly, this hanging mould can act as a barrier during the pouring process and, secondly, can effectively and below the template to flatten. The played an important connection role between template and template.

b.Yin and Yang Corner Mode Node Processing

Yin and Yang corneas are connected to the template in different ways. For the female corner moulds, the phenomenon of forced extrusion causes the female corner moulds to be skewed towards the inside of the wall during the actual construction process. Therefore, a specially designed yin corner mould pulling device is used. Adjustments; For the male angle die, due to its force opposite to the female corner die, welding techniques are required to weld the node to a rigid corner to withstand greater tangential forces. Hook bolts are used to fasten the rectangular backs, and the large formwork is fixed with the corner bolsters through the wall bolts to make it more secure. After this type of treatment, the horn mold can better prevent the leakage of the slurry, and is more aesthetic.

c. Treatment of D-type wall

Because the structure of the D-shaped wall is relatively stable and requires less external support than the floor, it is common to use an overall large formwork irrespective of the manner in which the D-shaped wall is connected to the next large formwork. The actual construction in Figure 2 is significantly easier than the two nodes above.

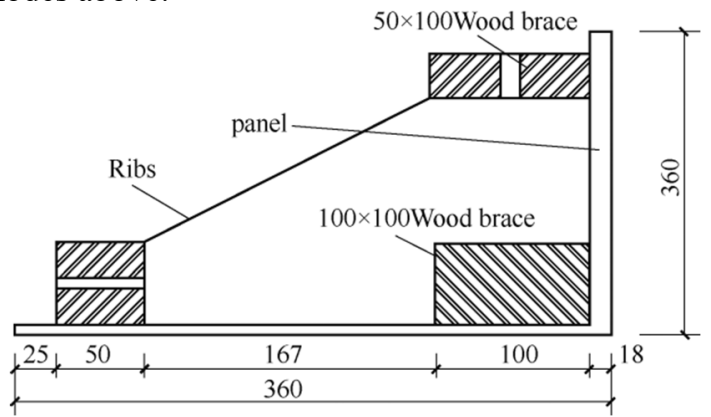

Figure 2 Yin angle template 


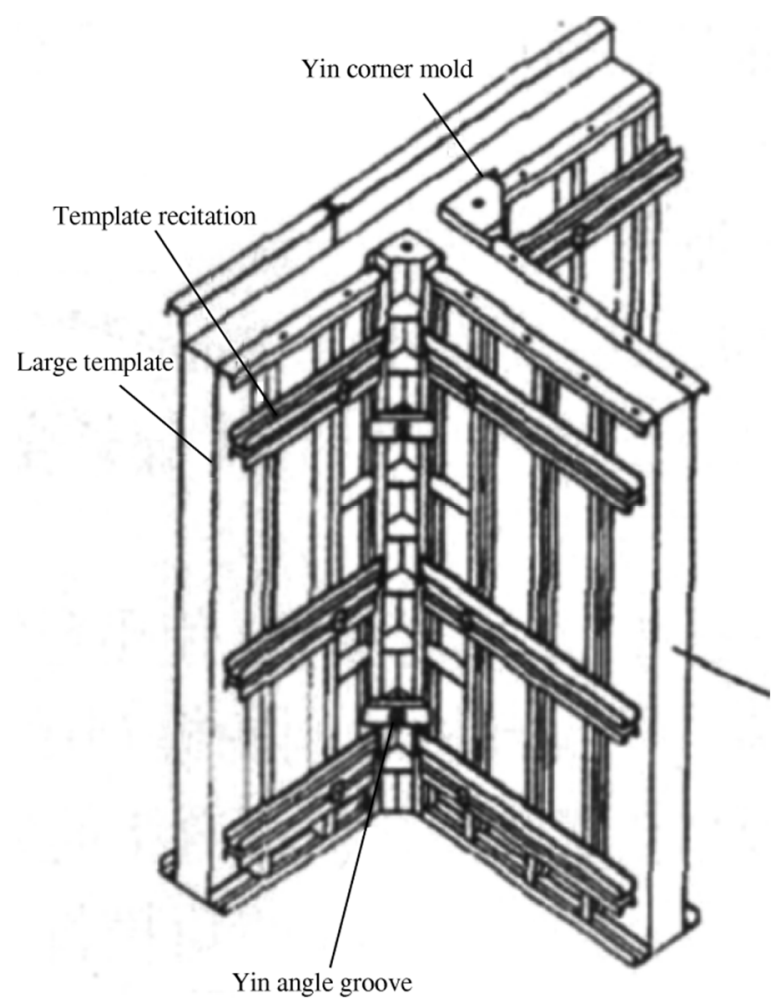

Figure 3 nodal treatment of a T-shaped wall

Because the structure of the D-shaped wall is relatively stable and requires less external support than the floor, it is common to use an overall large formwork irrespective of the manner in which the D-shaped wall is connected to the next large formwork. The actual construction in Figure 2 is significantly easier than the two nodes above.

Because the structure of the D-shaped wall is relatively stable and requires less external support than the floor, it is common to use an overall large formwork irrespective of the manner in which the D-shaped wall is connected to the next large formwork. The actual construction in Figure 2 is significantly easier than the two nodes above.

In the construction process of all steel large templates, there are some construction details that need attention. First, the door and window should be reduced by $15 \mathrm{~mm}$ on the side, because when the door and window are installed, the wall can be covered directly, so no need to close the mouth. In addition, in order to strengthen the joint strength of the seam, the surface of the shear wall should be indented by $90 \mathrm{~mm}$, and a steel wire mesh should be added to fix the wall surface. Finally, for the walls that need to be provided with air conditioning holes, the traditional method should be abandoning the design. The casing of air conditioning holes should be placed on the steel bars in the wall. However, in the actual construction process, the displacement of the steel bars cannot be determined and the location is not guaranteed. So the improved way is as follows:

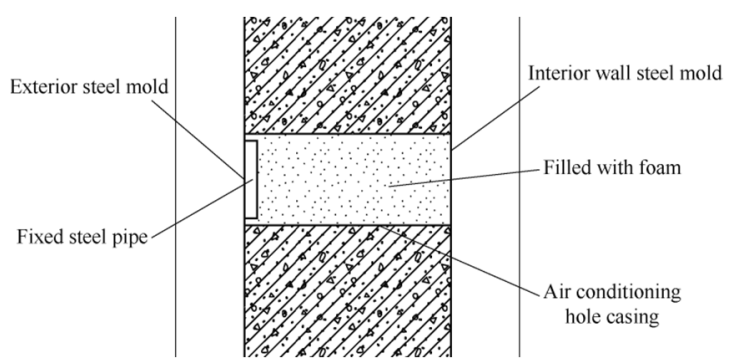

Figure 4 air conditioning port processing

The steel pipe is welded and fixed in the wall surface, the interior of the steel pipe is filled with sawdust, the casing of the air-conditioning hole is placed inside, and the filling is fixed by the sawdust. This improved method can reduce the displacement of at least $6 \mathrm{~mm}$ compared with the conventional method.

(2) Demolition of the Template

The installation of the formwork should be carried out in a well-designed sequence and cannot be changed at will during the actual construction process. When disassembling, it should be done in strict accordance with the order of installation, using professional tools for disassembly, to avoid damage to the molded wall and formwork.

The processing of large stencils and small stencils shall be carried out on different platforms. The smoothness and flatness of the stencil shall have certain requirements, so that the deviation of the assembled stencils at the joints is less than $0.5 \mathrm{~mm}$. The cleaning of the corner die should be carried out every time the large formwork is disassembled, and measurement corrections should be made to avoid the occurrence of slurry leakage during re-use.

\subsubsection{Concrete Works}

Before the concrete is poured, the entire template should be cleaned of debris. After the entire template is clean, fill with clean water and wait until the interior is wet before pouring concrete. The first step of pouring is to inject $60-110 \mathrm{~mm}$ cement mortar at the edges and corners. After the completion, a suitable amount of clean stone should be added on the top so that the stress inside the concrete can be equalized and the strength of the entire formed concrete can be approximated. the same.

The selection of vibrators is generally inserted. In order to ensure the molding quality of concrete, professional construction personnel should be used for vibrating. Vibrators should be stratified, but each vibrator should be drilled down to $60 \mathrm{~mm}$ below the next layer. Every layer is completely vibrated. It should be noted that during the vibrating process, the vibrator should be inserted at a high speed and pulled out at a slow speed. Attention must be paid to the internal reinforcement and embedment. By keeping the concrete humidity constant, it can prevent the concrete from shrinking. When the temperature is high, the humidity is increased, and when the temperature is low, a proper balance is maintained.

In the process of vibration, the strength and range should be as uniform as possible. For example, in the process of wall pouring, it should be ensured that the vibrating angle is the same, the amount of concrete added 
in a single time is small, and vibration is performed in order. When the surface of the concrete is uniform and bubbles are close to nothing, vibrate again. When the feeding device is too high, the concrete should be added in a serial manner.

\subsubsection{Mold removal and maintenance}

Demolition of concrete formwork should be carried out in accordance with relevant standards. It should not be put on hold for too long. Adhesion is not conducive to surface smoothness; nor can the concrete be solidified beforehand. It is also necessary to maintain the concrete formwork on time, and the material used for curing cannot fade, causing it to damage the entire concrete appearance. In the early stage, because the hardness of the concrete has not yet reached the requirements, professional personnel are required to perform maintenance until the maintenance reaches the required design requirements.

\subsubsection{Finished product protection}

The most vulnerable parts of concrete castings are the yin and yang corners. If they are damaged, they will not only damage the appearance of the finished concrete products, but often cannot meet the quality requirements. The yin and yang angles can be protected by the following methods: First, the positions of doors and windows, corners, and so on,it can be protected by fixing the slats; for some of the plastic switch boxes on the walls, protection can be achieved by using plastic cover protection.

\section{Conclusions}

With the continuous advancement of our country's architectural engineering technology, residents' aesthetic requirements for architecture have also been continuously improved. As a kind of decorative concret, the fair-faced concrete has gradually been favored by people. In itself, the advantage of saving the material cost also makes it has a great promotion significance. However, in the process of construction, there are still many problems worthy of our exploration. The research in this paper is only a brief exposition of the existing technologies. We hope that more people in the construction field will be involved in this research.

\section{References}

1. Feng Xiaoquan. Discussion on construction technology of construction of ready-made concrete [J]. Jiangxi Building Materials, 2015 (20): 121+127.

2. Yang Yong. On the construction technology of fair-faced concrete in construction project[J]. Sichuan Cement, 2014(11):180+188.

3. Chen Xiaoyan, Shang Yunfei. Discussion on construction technology of fair-faced concrete in building construction [J]. Henan Building Materials,
2013(06): 73-74+78.

4. Cheng Ming. Discussion on Construction Techniques for Modern Construction of Fair-faced Concrete[J].Guangdong Science and Technology,2012,21(05):149-150.

5. Yuan Zhihui. Application of the construction technology of the fair-faced concrete in the construction project[J]. Building Knowledge, 2010, 30(S1): 79-81. 